\title{
Power Quality Analysis of Wind Turbines. Part I - Static Analysis
}

\author{
Joaquín Mur Ángel Antonio Bayod Roberto Zapata Samuel Ortiz
}

\begin{abstract}
This paper shows a study on Power Quality (PQ) analysis of Wind Turbines (WT) installed in wind farms. A specifically designed measurement system has been installed in three wind farms with three different types of asynchronous generators of $600 \mathrm{~kW}$ and $700 \mathrm{~kW}$ classes.

- Conventional, squirrel cage induction generator directly connected and with fixed pitch (SQIG).

- Wound rotor, induction generator with external variable resistance and variable pitch (VRIG).

- Doubly fed asynchronous generator with external variable resistance and variable pitch (DFIG).

This part shows static relationships among active and reactive power, voltage drops and harmonics. In the second part, a dynamic study has been performed, focused on transient, connection and disconnection events.
\end{abstract}

Index Terms - wind energy, power quality, harmonics.

\section{INTRODUCTION}

$I^{2}$ nternational Standard IEC 61400-21 has been developed to define and specify the measurement to quantify PQ of a grid-connected turbine [1]. However, this standard limits mainly flicker emission and this is a secondary problem in Spain due to a) the connection of wind farm to PCC of fault level at least 20 times the nominal power of the wind farm b) complex orography, that desynchronise rotor fluctuations and randomise connection and disconnection events from one turbine to another.

There are also available drafts of standard for characterization of PQ, as IEEE P1159.1 [2] and IEC 61000-4-30 [3]. Standard IEC 50160 [4] describes at PCC the characteristics of voltage parameters in distribution grids in normal operation conditions.

In the first part of the paper, conclusions derived from 1 min and $10 \mathrm{~min}$ measures will be presented. Theses integrating periods allow studying stationary behaviour and power performance of the turbine [5]. One advantage of these measuring periods is the smoothing effect that filters oscillations and noise present in wind and in other signals. Therefore, graphics are clearer, data corresponding to longer measuring campaigns can be shown in the same plot and conclusions can be drawn easier.

To accomplish the PQ static analysis, average values of 1 to 10 minutes are measured at WT and substation. These data

The authors are with CIRCE Foundation and the Electrical Engineering Department of Zaragoza University, Spain, (Tfn 349767619 20, Fax 34 9767622 26, e-mail: joako@ posta.unizar.es).

The authors thank CEASA (Compañía Eólica Aragonesa S.A.) and TAIM-NEG-MICON by their essential support for this work. This work was also supported in part by Department of Education and Culture of Aragón (B134/98 grant).

The authors also thank Daniel Romanos, Roberto Sierra and Nacho Palacios for their contributions to the measurement system and for helping carrying out the installation of the system in the wind farms. can be easily obtained from the data-logger of the meteorological tower and from electrical network analysers.

Notwithstanding this fact, long measuring intervals have some drawbacks. Transients are neglected. Some effects like power fluctuations and current inrush at connection or disconnection can only be seen if shorter integrating periods are employed. In some cases, RMS or mean values are measures not quick enough, so some studies require the availability of waveforms or instantaneous values.

Most of the available supply network analysers do not allow neither the recording of signals at high sampling rate for long periods nor complex calculus with the acquired data. This can be a burden when performing a dynamic analysis.

The Electrical Engineering Department of the University of Zaragoza and CIRCE Foundation have developed a measurement system for dynamic analysis [6]. The main system is composed by a PC computer, a DAQ (Digital Acquisition Board) and signal conditioning modules. It can be placed in the low voltage side of a WT or connected to the measuring transformers of the wind farm substation.

\section{ANALYSIS OF DATA}

The fundamental variables of wind turbines have been related to generator speed, pitch, electrical power and wind speed and the information given by the manufacturer has been checked.

Two types of studies have been carried out:

- static analysis, focused on finding relationships among active and reactive power, voltage and wind in continuous operation.

- dynamic analysis, focused on connection events, transients and power fluctuations.

Both types of studies complement each other. Consequently, an integral study of a wind farm or a wind turbine will involve the combined use of several techniques, measurement intervals and measures at the turbines and at the farm substation.

To accelerate the process of analysis, some programs and scripts to visualize graphs have been developed, but analysis of an expertise is still irreplaceable.

\section{MEASUREMENT SYSTEM}

The measurement system was installed in two wind farms owned by CEASA with wind turbines in the $600 \mathrm{~kW}$ class. Both farms have wound rotor asynchronous generators and variable pitch. One farm has wound rotor induction generators with a variable resistor connected to their rotor (VRIG), from Vestas. This fact makes generator speed vary from 1500 to $1560 \mathrm{rpm}$. The other one utilise doubly fed induction generators (DFIG) from Gamesa, with generator speed from 1220 to $1620 \mathrm{rpm}$.

It was also installed in a wind farm owned by TAIM-NEGMICON, with wind turbines in the 600 and $750 \mathrm{~kW}$ class and with fixed pitch (stall control). The utilized generators are 
squirrel cage induction generators (SQIG), one speed, directly connected to the network. The $600 \mathrm{~kW}$ WT has a solo generator, with one fixed speed (1500 to $1514 \mathrm{rpm}$ ). The $750 \mathrm{~kW}$ wind turbine employs a secondary $200 \mathrm{~kW}$ generator to increase production at low wind by reducing rotor speed (1000-1006 rpm versus 1500-1510 rpm).

Signals that come from the top and from the ground of the wind turbines enter the box as it is shown in Fig. 1. Measurement transformers have been used to acquire instantaneous voltage and current waveforms.

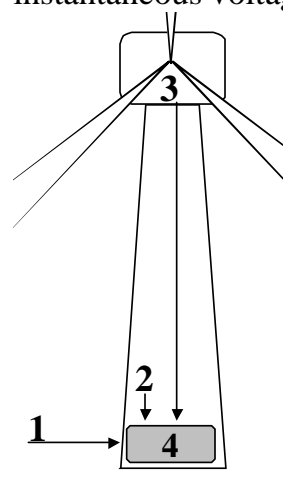

\section{Data from meteorological tower} (wind speed and other slow varying signals).

2. Electrical parameters of WT:

- Phase-to-neutral voltage $\left(\mathrm{V}_{\mathrm{R}}, \mathrm{V}_{\mathrm{S}}, \mathrm{V}_{\mathrm{T}}\right)$.

- Stator currents $\left(\mathrm{I}_{\mathrm{R}}, \mathrm{I}_{\mathrm{S}}, \mathrm{I}_{\mathrm{T}}\right)$.

- Rotor currents $\left(\mathrm{I}_{\mathrm{U}} \mathrm{I}_{\mathrm{V}}, \mathrm{I}_{\mathrm{W}}\right)$.

3. Signals from nacelle of WT:

- Pitch signal.

- Generator speed signal.

- Turbine speed signal.

4. Steel box with the computer.

Fig. 1: Schematic of signals taken at DFIG WT.

Generator and turbine speed are measured with inductive sensors, which are easily installed. However, encoders give greater accuracy and they are preferable for squirrel cage generators, since generator speed has narrower intervals. Signals from WT sensors are isolated and transmitted in current loops or digitally by a RS-485 net to avoid interferences.

Wind speed is measured with an anemometer at a meteorological tower. Propeller and cup anemometers were employed. Propeller anemometer has quicker response, but the oscillating movement of the wind vane can introduce errors in turbulent winds. Other anemometers are feasible (sonic, laser, hot wire, SODAR, etc) and some of them have more precision, but they are not very reliable for this application and they can require temperature, humidity and pressure compensation [7, 8].

Wind is probably the main parameter of a WT farm. However, its spatial and temporal variability makes it hard to grasp. Complex orography, proximity of flow obstacles -as buildings or other WT-, and wind shear and tower shadow can affect notably torque [9]. Most anemometers give a local measure whereas it is preferable to obtain a spatial average over the swept area of a wind turbine, or for our application, even over the whole wind farm.

Nevertheless, this problem mainly affects the estimation of economic viability of a feasible wind farm or the control of variable speed or variable pitch WT. In order to decide whether to connect at low winds or to disconnect at high winds, the control typically uses a cup anemometer and a wind vane placed downstream on top of the nacelle (this signal is very noisy due to turbulence, but if it is low-pass filtered, it gives enough information for this task). An option largely implemented for blade or speed control in WT is to estimate actual average wind speed from generated power, angular speed and pitch angle.

Due to the difficulties to get precise measurements of wind, it is advisable, for power quality analysis, to focus on electrical parameters of the farm instead of the wind speed [10].

In addition to the measures achieved at the turbines, the system has been placed in the substation of the farm. This has made possible to study the overall effect of all the turbines of a park in the point of common coupling (PCC). Substation parameters are measured at voltage and current transformers.

On the one hand, the effect of starting, stopping and power oscillations (due mainly to tower shadow and wind shear) is more easily studied locally at a single WT with waveforms or fast measures. On the other hand, the global effect of all WT should be analysed at the output of the wind farm (statistical dispersion of events and partial compensation of fluctuations play a key role in the overall behaviour of the system) [11].

\section{STATIC ANALYSIS}

The fundamental variables of wind turbines have been plotted versus generator speed, pitch, electrical power and wind speed. The information given by the manufacturer is checked.

The testing of the power curve of wind turbines is important in operation and maintenance (O\&M). In case of malfunction, charts as active power versus wind speed can show up the reason. At this point, the wind directions affected by near obstacles (for example, other turbines of the farm) and flow distortion have to be taken into account, as pointed in IEC 61400-12. This fact was critical in the sites analyzed, placed mostly in complex terrain, since they are not suitable for power performance testing.

Estimation of actual mean speed all over the swept area of the WT would be the main parameter of the static analysis. Aerodynamics and regulation can make power above rated speed more stable than below, due to pitch regulation or stall. Thus, the overall behavior of the WT depends on the point of functioning. Nevertheless, the experience gained from several studies accomplished by our group, has lead to the conclusion that, in power quality analysis, most studies can be based in active power output of generator as main parameter, instead of the wind. The total output of the WT is also suitable, but it is less precise since consumption of auxiliary devices is not constant.

Other point of static analysis is the election of integration time. If integration time is too small, graphics can be confusing and fuzzy due to the apparition of dynamic effects and the presence of excessive number of points. In contrast, if integration time is too large, one datum can represent different working points, so the graphic is distorted. The optimum election depends on the analysis being made.

\section{A. POWER CURVES}

Figure 2 shows the power curve of DFIG -every point in the graph represents mean power in one minute-.

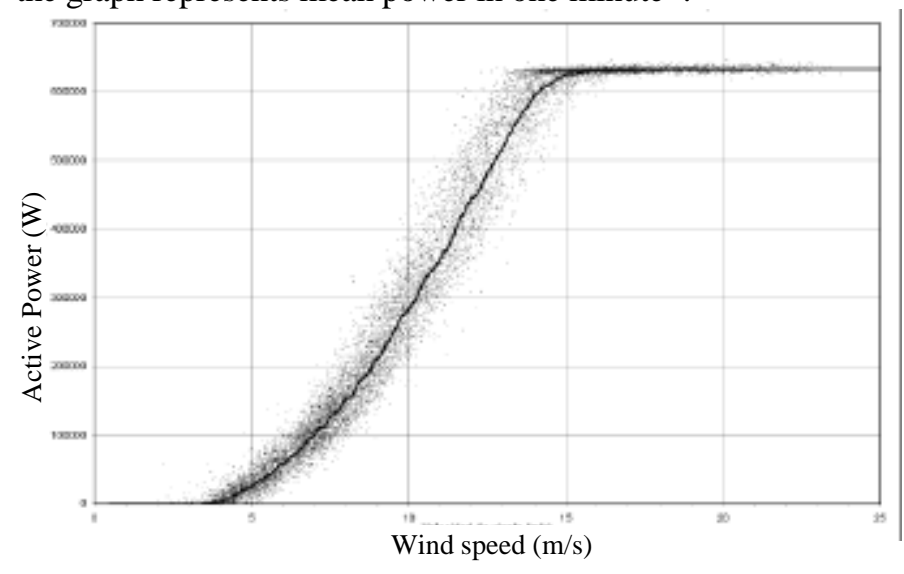

Fig. 2: DFIG power curve based in 1 min mean values is suitable for checking manufacturer data. 
It can be seen that the points in the chart are quite dispersed, but on average, they corroborate manufacturer data (mean value of data is drawn in solid line.

One minute can be used as time interval instead of $10 \mathrm{~min}$ to check power curve with shorter measurement stage. It does not accomplish IEC 61400-12, but larger number of points is obtained, especially at high winds where probability of occurrence is low. However, if we utilize a second as averaging period, the scattering of the measured power curve is excessive, blurring the figure (Fig. 3).

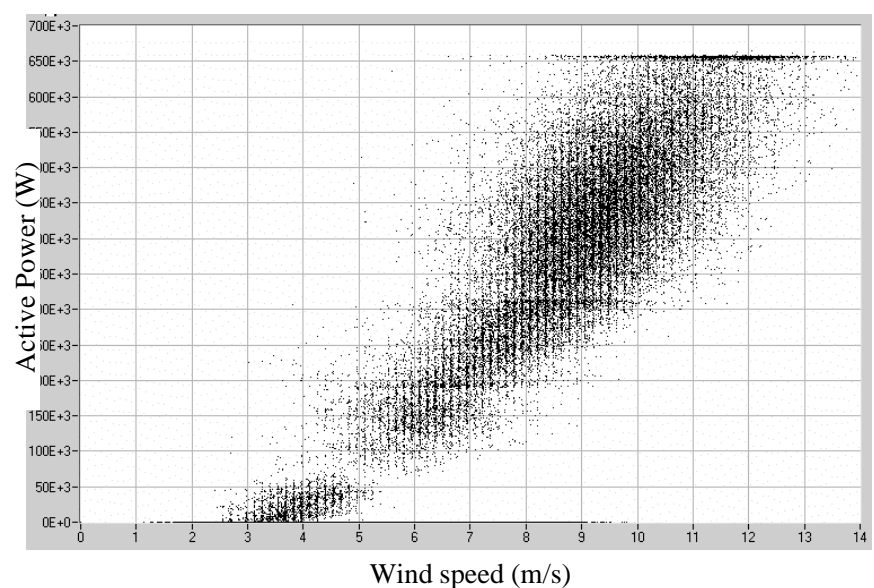

Fig. 3: DFIG power curve based in 1 second mean values shows excessive scattering.

Power curve of a wind farm can be also measured (see Fig. 4). Depending on the wind direction, some turbines produce more than others due to nearby obstacles and farm layout. The wakes of turbines can even affect the meteorological tower and misrepresent the measured wind. One solution is to obtain one power curve for each important wind direction and correct wind speed when the meteorological tower is affected by wakes. The upper and lower lines represent, for each wind speed bin, the standard deviation of measures.

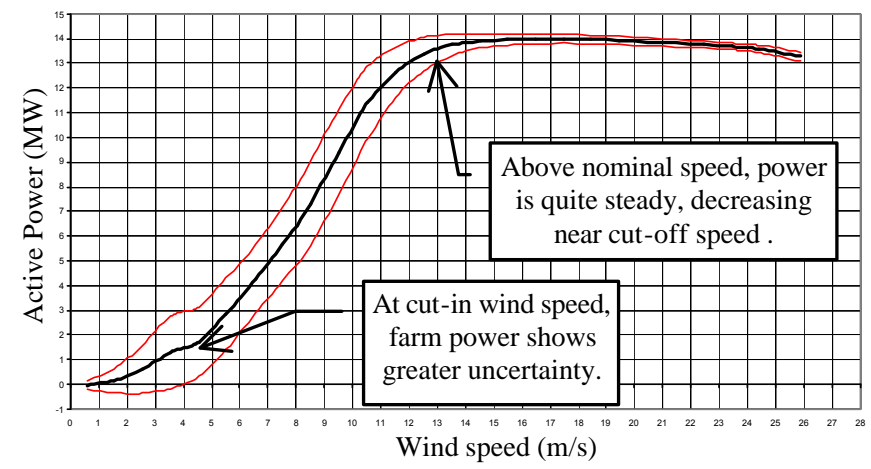

Fig. 4: power curve of a VRIG farm based in 1 second mean values (thin lines contain $68 \%$ of values).

\section{B. HARMONICS}

On the studied cases, current harmonics of high order at WT are lower than voltage harmonics, due to the low distortion of current injected by generators. IGBT power converters of DFIG WT produce high frequency harmonics in voltage, but distortion in current is low due to the high inductance, at high frequencies, of the transformer and the filter choke. In DFIG, the frequency of harmonics are corresponding to the switching of IGBT (around $8 \mathrm{kHz}$ ). The main effect of this harmonics is related to interference with signals and electronic devices (apart from the increase of losses in magnetic cores and capacitors). For example, some "true RMS" millimetres have shown deviation up to $30 \%$ when measuring voltage of the tertiary winding of the transformer where the power converter is connected. Other effect of the high frequency harmonics is the induced current that can circulate trough the bearings of the generator, degrading the lubricant and provoking premature failure of bearings.

Nevertheless, this high frequency harmonics are only of importance inside the turbine, because they are largely filtered by the high impedance of transformers at such frequencies (and, in second place, capacitance of cables) [12]. These harmonics are not in phase from one turbine to another, so they partially cancel and they don't affect the grid.

At substation, only low order harmonics (3, 5, 7 and surprisingly 2,4$)$ have been found. In one farm where this effect was remarkable, the presence of even harmonics is confirmed in the waveforms, which were not symmetrical. This can be the origin of some random firing of homopolar voltage protection at the substation. This has happened even with still turbines, so this fact has been attributed to the connection of the farm at the end of a long line with many consumers.

Current harmonics are only important during switching operations; especially during thyristor soft start events that occur mainly around 4 to $5 \mathrm{~m} / \mathrm{s}$ wind speed. Fig. 5 displays current harmonic residue versus wind speed (thin lines represent the limit containing $68 \%$ of measures). Harmonic residue has been plotted instead of THD -total harmonic distortion- since, during switching operations, RMS value of distortion is comparable to fundamental component (compare with Fig. 7).

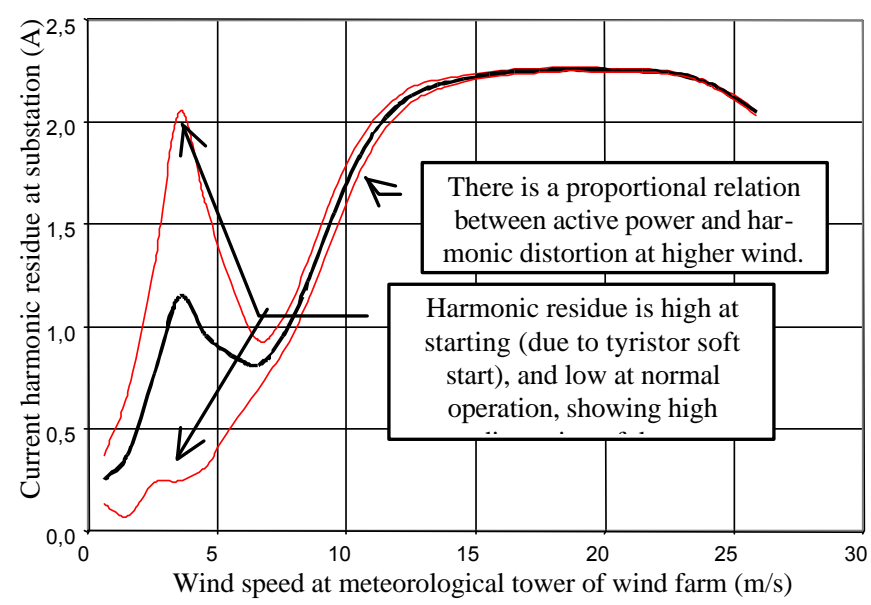

Fig. 5: Current harmonic residue at VRIG substation versus wind speed at meteorological tower.

However, current waveform distortion during normal WT operation (not transients) greatly depends on the network. Current distortion during steady operation is quite influenced by distortion in the voltage supply. In Fig 6, you can see that the harmonic residue of current and voltage at WT are related most time, independently of farm power.

Harmonic residue has been plotted for current harmonic analysis in some graphics. The absolute value of distortion is better related to magnetic core loses and hence, residue is more suitable variable than THD. THD can give, at first sigh, a false idea of being critical the harmonics at low power. THD levels at low power can be very big because the distortion can be comparable to fundamental component of current 


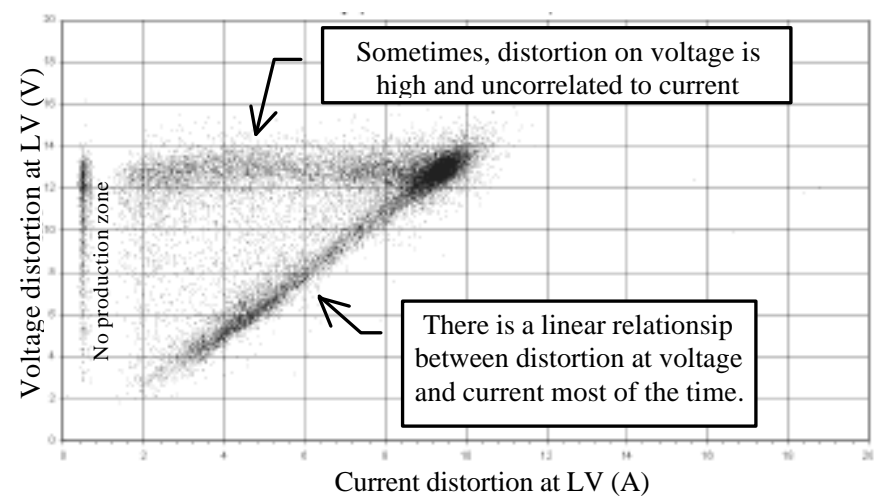

Fig. 6: Current harmonic residue versus voltage harmonic residue, measured at low voltage side of a VRIG WT.

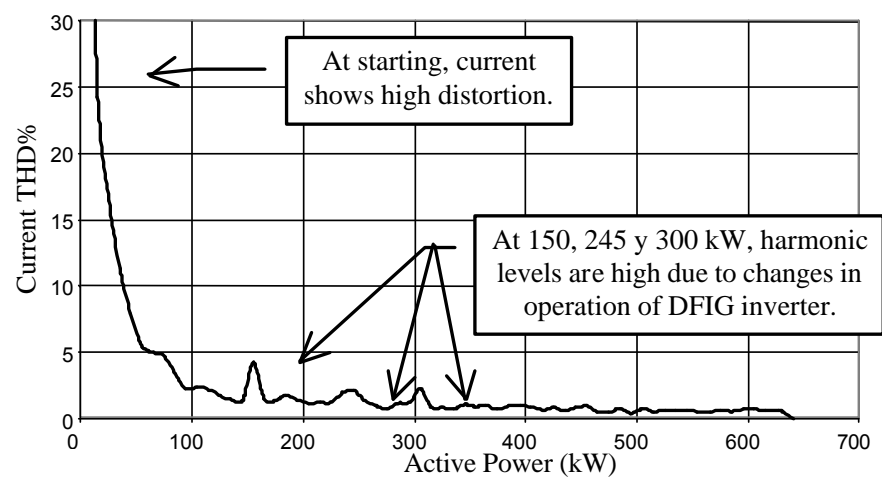

Fig. 7: Current THD\% versus active power, measured at LV side of a DFIG WT.

\section{VOLTAGE VARIATIONS}

Voltage variations due to a generator can be approximated by:

$$
\Delta U \approx \frac{R_{s c} \cdot P-X_{s c} \cdot Q}{U^{2}} \quad \text { (p.u.) }
$$

In Fig. 8, there is a clear relationship of voltage with power output at WT LV side due to high short circuit impedance $Z_{k}$ after substation transformer and cables (power transmission from WT to substation is made at $690 \mathrm{~V}$, so $\mathrm{Z}_{\mathrm{k}}$ is quite resistive). In the other cases studied, where a MV network was employed to connect the turbines with the substation, it was no evident relation between active power output and voltage at the substation (the compensation of reactive power takes place in the turbine, so the inductance of transformers and lines only affects appreciably during switching events, where the current is quite reactive).

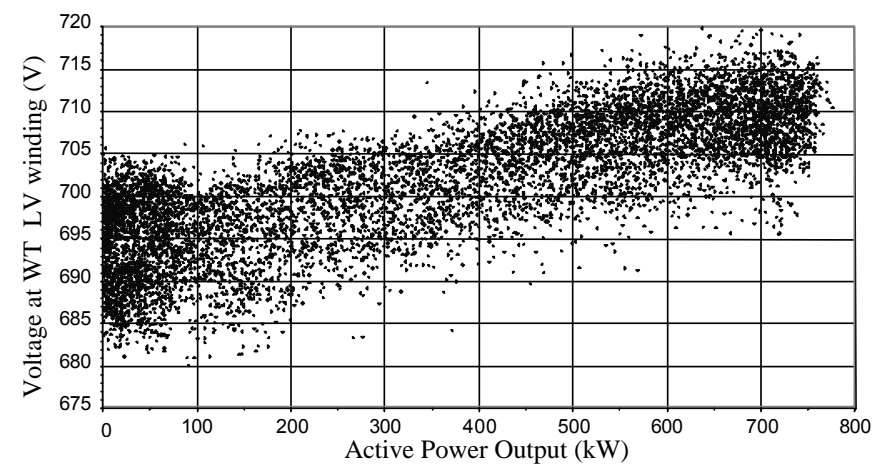

Fig. 8: Voltage versus power output at a SQIG WT connected to a quite resistive line.

According to this fact, major voltage fluctuations at substation are essentially due to the resistance of conductors, other consumers of reactive power, changes of topology and manoeuvres, especially in long distribution lines. In some sites, the influence of active power in voltage is very weak even for measures at LV winding of a WT owing to a short circuit impedance $Z_{k}$ angle near $90^{\circ}$ (there is a transformer in the WT and cable lines are not too long).

For example, grid regulation caused variations at $66 \mathrm{kV}$ line of VRIG wind farm (grey line in Fig. 9), while voltage of $45 \mathrm{kV}$ line at DFIG wind farm (black line) was quite steady. The wind farm in grey is placed at the end of a long $66 \mathrm{kV}$ line, where the addition of line consumers and line regulation has predominant role (the voltage steep changes in the grey farm are not related to power). In contrast, the black farm is connected to a PCC (point of common coupling) with greater fault level and it has steadier voltage.

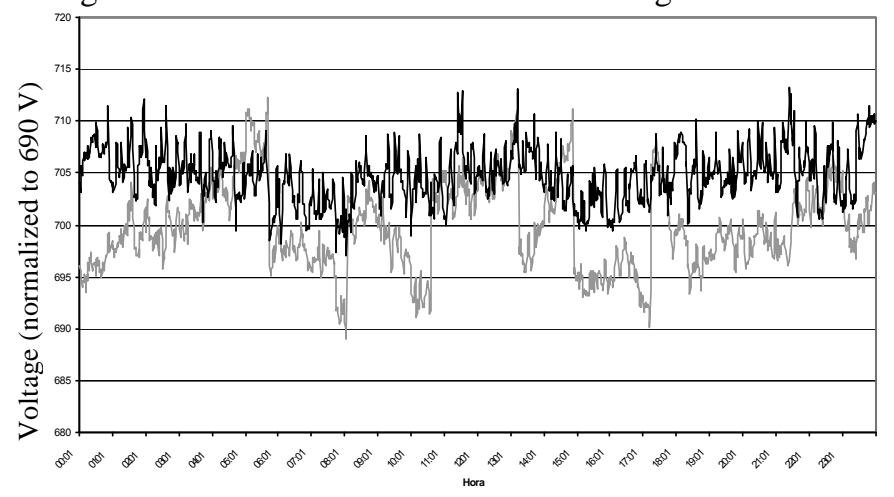

Fig. 9: Voltage at two wind farms output line with similar power generated and around $60 \mathrm{~km}$ apart.

In spite of being quite close geographically, the two wind farms are remote electrically. This fact can also be noticed in other example, when voltage of DFIG wind farm presented occasionally $2,5 \%$ unbalance, independently of power and causing up to $3 \%$ loss of performance. Theses behaviours are independent of the main parameters of the farms, so they should be imputed to a change in topology at PCC.

For the cases studied, where wind power is small compared with the loads, the influence of wind farm is usually low. Thus, the rest of the grid masks possible affections of wind power to voltage. Therefore, the main problem related to static voltage analysis is to obtain representative data of the grid at key points; otherwise relationship between wind farm active and reactive power and voltage is so fuzzy and blurred that no relationship can be stated.

In Fig. 10, the voltage dependence with power is comparable to the standard deviation. The upper and the lower lines contain the $68 \%$ of measured data (the upper and lower lines are drawn computing adding and subtracting the standard deviation for each bin of power). Even though any conclusion from Fig. 10 can be questioned due to the large statistical dispersion, there could be a tendency of decrease of voltage In 1 to $3 \mathrm{MW}$ due to very inductive inrush currents at connection and disconnection. Above $4 \mathrm{MW}$, there is a slight tendency of rising voltage, due to the characteristics of the line where the wind farm is connected (the end of a long distribution line). When the wind farm is near maximum output, voltage seems to reduce a little because the WT begins to consume inductive power (capacitor banks can not fully compensate inductive power of generator). 


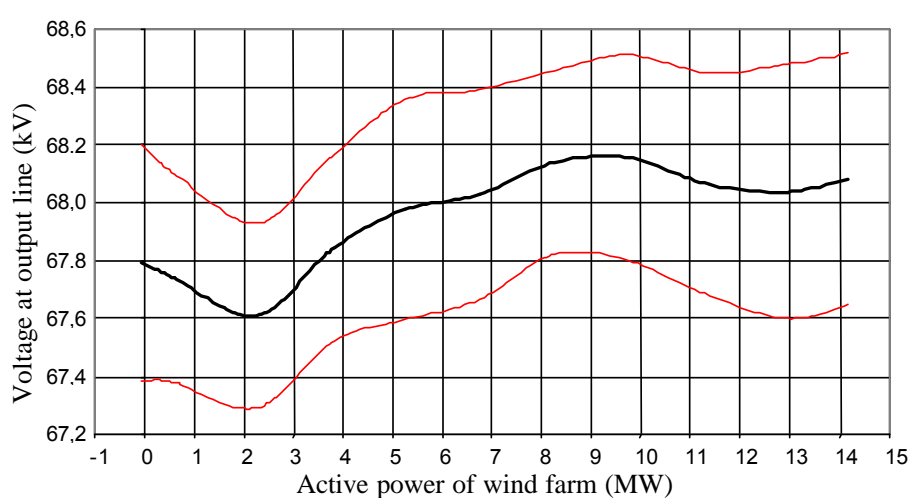

Fig. 10: Voltage versus power output at a wind farm.

Simulation can be more useful to determine the performance, since all consumers can be controlled. The main problem in such simulation is to get a representative model of a wind farm.

Nowadays, there is a tendency to increase power rating of wind farms, to connect wind farms to higher voltage with dedicated lines, to use tap changing transformers and may be, to manage reactive power.

\section{REACTIVE POWER.}

Present regulation at Spain demands and rewards unit power factor at substation. SQIG and VRIG WT need capacitor banks to compensate inductive reactive power consumed by generator. In most WT models with capacitor banks, they are sized to nearly compensate reactive power. At low capacity factors, capacitor can fully compensate reactive, but at higher loads, the WT consumes inductive reactive power.

At around cut-in wind speed, power factor at wind farm is low. This is due to the high inductive current at connection. This current is gradually compensated until all needed capacitor banks are connected (this can require between $15 \mathrm{~s}$ and 1 min, depending on the control of the WT). In addition, the capacitor banks are disconnected some cycles before the generator to avoid its self-excitation (that could lead to dangerous over voltages). As connection is a slower event than disconnection, connection has greater effect in the overall reactive behaviour of the farm.

Fig. 11 shows three connections of a VRIG WT with wind around cut-in speed, where control has decided to connect (thicker black line represents reactive power - computed as $\mathrm{Q}=\mathrm{V} \cdot \mathrm{I} \cdot \operatorname{sen}(\varphi)-$ and the thin grey line represent active power). But as soon as there is a connection, wind speed decreases and the WT begins functioning as a motor (active power negative) for some seconds and the control disconnects the WT. The glitches in the graph are due to auxiliary consumption (hydraulic pumps, servomotors, etc).

Another problem that arises if wind speed is not very steady is that it can lead to frequent switching of capacitor banks. Apart from the apparition of transitory events in waveforms, studied in part II of this paper, frequent switching decreases overall power factor: if reactive power consumed by generator varies considerably, power factor correction would try to follow theses variations. However, as the frequency of switching is limited by the control of capacitor banks, compensation level will be reduced because it is not quick enough.

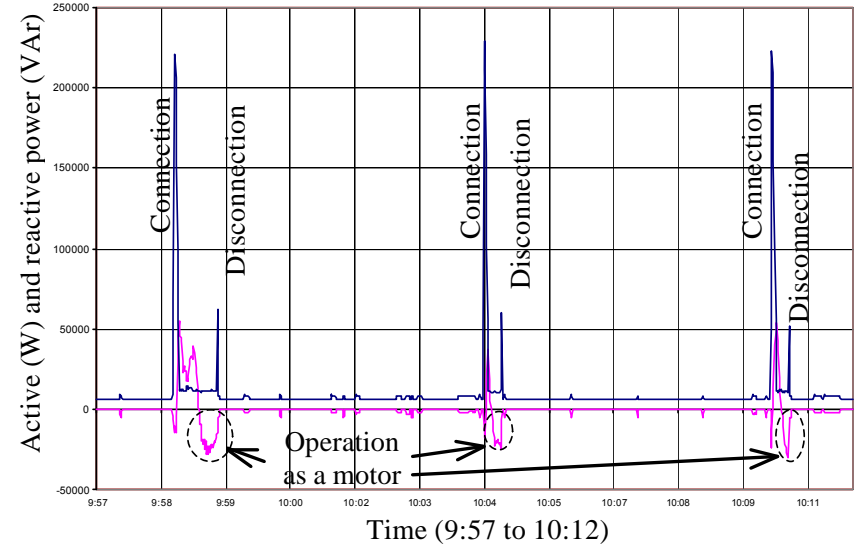

Fig. 11: Three failed connections of generation due to low wind at a VRIG WT.

This problem is aggravated in frequent connexion and disconnection of the WT, since all capacitor banks are switched and there is more probability that the limit number of connections could be reached. If capacitor banks and WT control are not integrated, the WT can operate some time without reactive compensation, as Fig. 12 shows.

Fig. 12 is an example of a control that is not adjusted to gusty wind and produces frequent connections and disconnections of the generator. From 9:50 to 9:51, the WT operates without reactive compensation due to the maximum number of switching of capacitor banks have been reached. At 9:51, the generator is disconnected because it is operating as a motor. A short while after, the wind increases and the turbine tries to generate. However, the last step of the capacitor bank is not connected. Then, the generator is again functioning as motor and quickly disconnect. 20 seconds after, the generator is connected, operating the first 15 seconds without reactive compensation. After 1 minute and 10 seconds, the generator finally is disconnected.

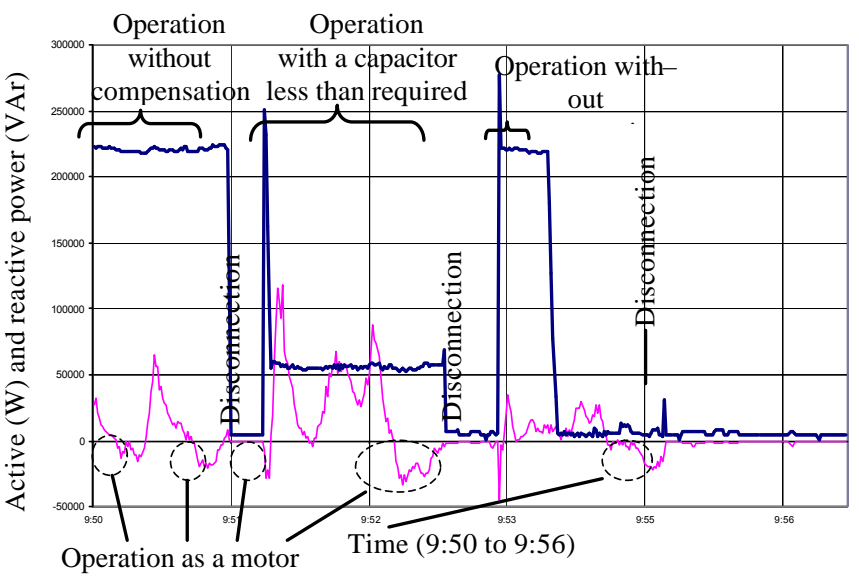

Fig. 12: Active and reactive power of a VRIG WT.

The relationship of active and reactive power can be derived plotting $\mathrm{Q}, \varphi$ or $\operatorname{Cos}(\varphi)$ versus $\mathrm{P}$. The phase angle $\varphi$ is a bit confusing because at connection, it varies from $-150^{\circ}$ (WT is an inductive load) to about $-30^{\circ}$ or less (WT is an inductive generator). In addition to this, the measurement of angle has high uncertainty when the WT is not generating (mainly due to the high relative error on current measurement) and auxiliary periodic consumption causes considerable jumps in $\varphi$ at no production. $\operatorname{Cos}(\varphi)$ shows a more stable behaviour and can be a good choice, specially if 
long averaging periods are employed (for power factor near the unit $\frac{\mathrm{d}}{\mathrm{d} \varphi} \cos (\varphi)=-\operatorname{sen}(\varphi) \approx-\varphi \approx 0$ and hence $\cos (\varphi)$ is less sensitive to power variations). If the averaging period is short, $Q$ versus $P$ plot is more adequate, since power factor at substation is not the arithmetic average of $\varphi$ or $\operatorname{Cos}(\varphi)$ but $Q$ at substation is the sum of $\mathrm{Q}$ of each WT (plus reactive consumption of transformers minus reactive generation of cables).

Active/reactive curves of a VRIG and of a SQIG are similar. In the WT analysed, VRIG has higher rotor resistance than SQIG, especially near nominal power. Measured reactive power confirms that static equivalent model circuit of induction generator is accurate enough for static simulations [13]. Dispersion of values shown in Fig. 13 to 15 can be imputed to dynamic effects and dependence of voltage on reactive power.

Another key point found in a number of WTs with capacitor banks is that even though they have several banks, all the capacitors are connected some seconds after the generator (a bit later to avoid self-excitation and harmonic resonance). The capacitor bank is sized to compensate mainly the magnetizing current of the generator. When power increases, reactive power consumption increases, due to leakage inductance of rotor and stator, about $100 \mathrm{kVAr}$ for a $600 \mathrm{~kW}$ generator. However, this reactive is not further compensated to cut down extra compensator costs and control complexity.

Fig. 13 shows the active / reactive curve for a SQIG WT with two generators, one for low wind speeds and other for higher output.

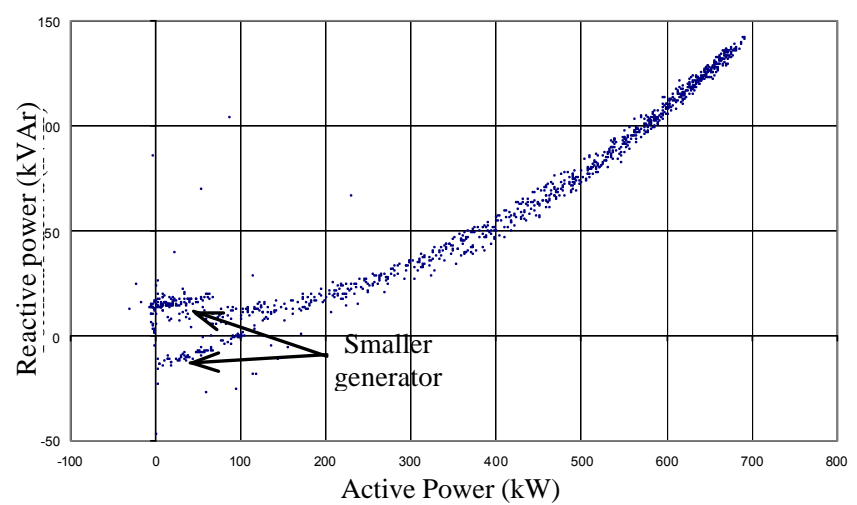

Fig. 13: Active and reactive power of a WT with two SQIG generators (200 kW, $1000 \mathrm{rpm}$ and $750 \mathrm{~kW}, 1500 \mathrm{rpm})$.

(1 min averages).

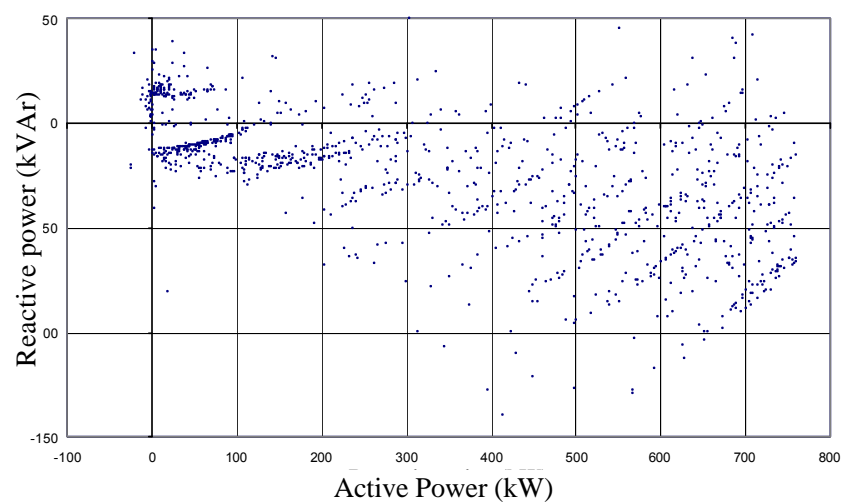

Fig. 14: Active and reactive power of a WT with two SQIG generators and full load compensation (1 min average values).
The same WT but with full load compensation is shown in Fig. 14, where it is clear visible how capacitor banks are switched (in this case, for high load level the WT generates reactive to compensate inductive consumption of WT and farm transformers).

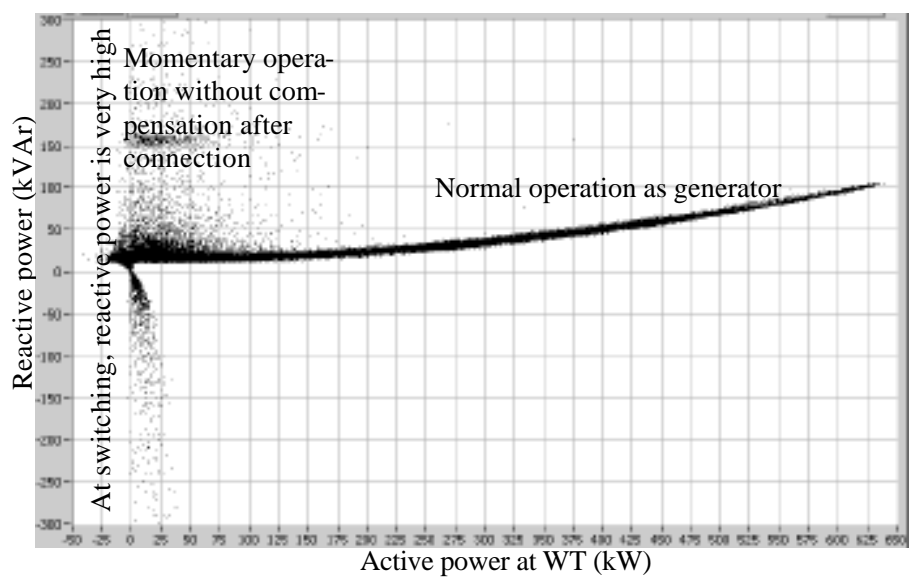

Fig. 15: Active and reactive power of a SQIG generator WT of $600 \mathrm{~kW}$ nominal power (1 min average values).

In contrast, DFIG can generate capacitive or reactive power depending on rotor excitation. In practice, reactive power of a DFIG is limited by heating of rotor and maximum current and DC bus voltage of power converter.

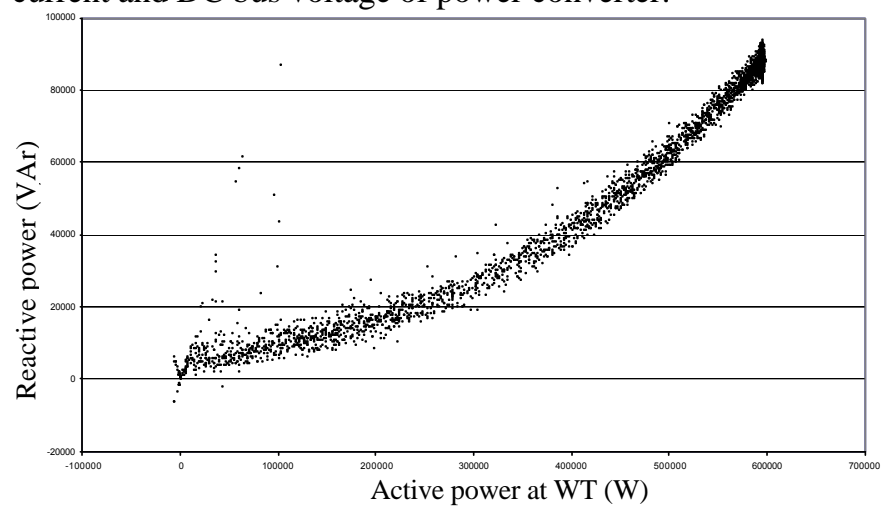

Fig. 16: Active and reactive power of a VRIG WT (1 min averages).

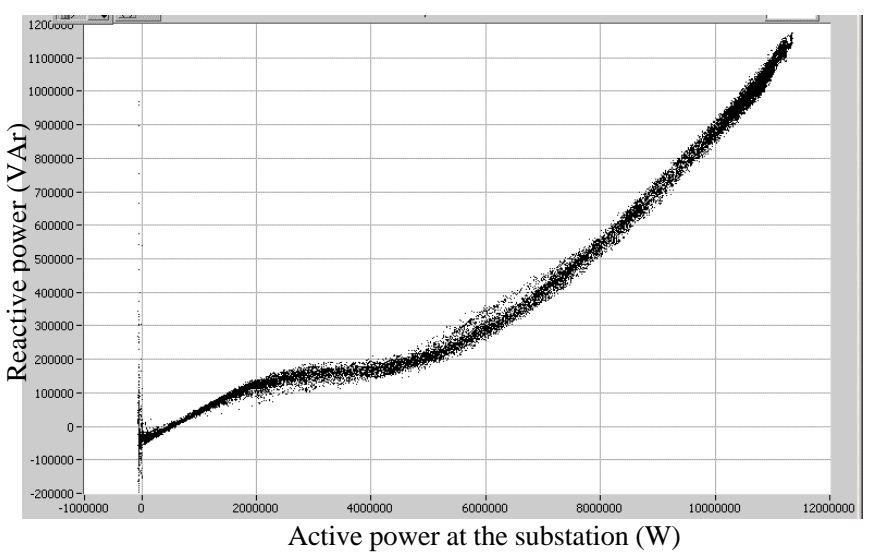

Fig. 17: Active and reactive power of a DFIG wind farm (1 min averages). 


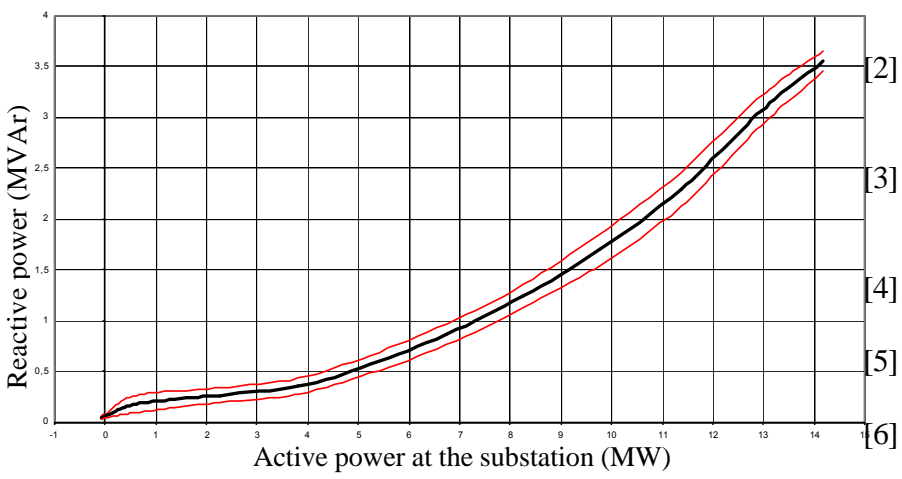

Fig. 18: Active and reactive power at output line of a VRIG wind farm (1 min averages).

\section{V.CONCLUSIONS}

A methodology for power quality analysis has been developed for wind farms and wind turbines. This part of the work corresponds to steady state analysis, comparing average of the main parameters of a wind farm and its wind turbines to assess possible relationship among them. The studied parameters have been power curve, stationary harmonics, voltage and its variation and reactive power.

The operation of WT with more common technologies has been compared from the network point of view. In addition to this, the impact of a single WT is compared with the farm where it is installed.

The measured data show that harmonics and voltage are correlated with operation parameters of a WT -at low voltage winding-, but relationship is very weak at substation due to the high fault level of PCC, filtering of transformers and cables, the influence of other consumers outside the farm and changes of network topology.

The impact of wind farms in voltage is low, since reactive power is low due to actual regulation. As resistive component of short circuit impedance is low in studied sites, the variations of voltage are mainly exogenous. Only is the affection of voltage important in weak networks with quite resistive networks or when current is quite reactive.

To correctly assess the impact of the wind farm in line voltages, a stochastic power flow is suitable because the origin of voltage variations can be very diverse in a real case. The problem with this simulation is to represent accurately the wind farm, but it can be done with data from this static analysis and with the model proposed in [14].

In a real site, especially at measured installations with complex orography, operation points of WT are continuously evolving and values at the substation correspond to the sum of near working points. If integrating period is long enough, some dynamic effects that are not important for a steady analysis can be masked and the study can be done more easily and with less requirements of memory in the measurement apparatus. However, if the integrating period is too long, a single datum can correspond to a number of operation points (in this case, the datum losses meaning and it can lead to wrong conclusions).

\section{REFERENCES}

[1] Wind Turbine Generator Systems-Part 21: Measurement and assessment of power quality characteristics of grid connected wind turbines, IEC61400-21.
Guide for recorder and data acquisition requirements for characterization of power quality events, IEEE Standard P1159.1. Draft available: http://grouper.ieee.org/groups/1159/1/

Electromagnetic Compatibility (EMC)-Part 4: Testing and measurement techniques. Power quality measurement methods 61000-4-30, Draft version.

[4] UNE-EN 50160 "Características de la tensión suministrada por las redes generales de distribución".

Wind turbine generator systems - Part 12: Wind turbine power performance testing., IEC 61400-12, Feb 1998.

M. Sanz, A. Llombart, Á. A. Bayod, J. Mur, "Power Quality Measurements and Analysis for Wind Turbines" IEEE Instrumentation and Measurement Technical Conference, IMTC 2000, pp. 1167-1172.

[7] A. Albers, H. Klug, D. Westermann, "Cup Anemometry in Wind Engineering, Struggle for Improvement", DEWI Magazin Nr. 18, February 2001. Available: http://www.dewi.de/dewi/magazin/ 18/04.pdf

[8] Ammonit, "Wind Measurement for accurate energy predictions". Available: http://www.ammonit.de/ knowhow.html

[9] D. A. Spera, "Wind Turbine technology". ASME Press, 1994. Chapter 8: Characteristics of the Wind.

[10] F. Santjer, G. J. Gerdes, R. Klosse. "Power Quality Measurements at Wind Turbines". Power Quality, June 1997 proceedings, pp 283-292

[11] G. McNerney, R. Richardson, "The statistical smoothing of power delivered to utilities by multiple wind turbines," IEEE Transactions on Energy Conversion, Vol. 7, No. 4, pp. 644647, Dec. 1992.

[12] Heier, Siegfried. "Grid integration of wind energy conversion systems". John Wiley \& Sons Ltd.

[13] Andrés E. Feijoo, J. Cidrás, J.L.G. Dórenlas, "Wind speed simulation in wind farms for steady-state security assessment of electrical power systems", IEEE Trans, on Energy Conv., Vol. 14, No 4, Dec. 1999, pp 1582-1588.

[14] J. Mur, J. Sallán, A. Bayod, "Statistical model of wind farms for power flow" International Conference on Renewable Energies and Power Quality (ICREPQ'03), Vigo, April 2003. 